\title{
Repliek: naar een Wikifonia
}

\author{
Marc van Oostendorp, Willem Visser en Daan Wissing
}

NT 23 (2): 141-149

DOI: 10.5117/NEDTAA2018.2.005.OOST

\section{$1 \quad$ Inleiding}

Het fonologiedeel van het Taalportaal is waarschijnlijk - het is niet gemakkelijk zoiets te kwantificeren - het kleinste van de drie onderdelen (naast fonologie ook morfologie en syntaxis) van deze website, die vanaf het begin af aan een zo volledig mogelijke beschrijving van de fonologie van het Standaardnederlands en het Fries heeft gegeven, waar die van het Afrikaans in een iets later stadium aan is toegevoegd. Samen zijn ze in ieder geval het begin van de verwezenlijking van een ideaal: alle door Nederlandse, Vlaamse, Friese, Zuid-Afrikaanse en andere onderzoekers in de loop van de afgelopen decennia verzamelde inzichten over de klankstructuur van deze drie nauw aan elkaar verwante talen aan de hele wereld ter beschikking te stellen.

De belangrijkste ontwerpbeslissingen in het Taalportaal zijn met dit doel voor ogen genomen. De taal van de beschrijvingen is het Engels, de vorm is digitaal en open access, bij de behandeling van de individuele onderwerpen is ervoor gekozen om deze zowel in uiterst korte vorm als in veel uitgebreidere vorm aan te bieden, zodat iedereen er iets van zijn gading kan vinden. Het doelpubliek bestaat in de eerste plaats uit collega-taalkundigen, zoals fonologen die in andere talen werken aan een bepaald verschijnsel (bv. klemtoon) en willen weten hoe een en ander er in de West-Germaanse talen voorstaat, of niet-fonologen (bv. experimenteel fonetici of sociolinguïsten) die bij hun werk te maken krijgen met een bepaald fonologisch verschijnsel en niet in de gelegenheid zijn zelf de uitgebreide literatuur over Nederlandse, Friese en/of Afrikaanse fonologie door te nemen. Daarnaast, maar nadrukkelijk op de tweede plaats, is 
er de mogelijkheid om het Taalportaal in te zetten bij de didactiek van het Nederlands als Vreemde Taal. En tot slot kan natuurlijk ieder die belang stelt in een gedetailleerde beschrijving van de grammatica van onze talen gebruik maken van onze informatie. Het is belangrijk op te merken dat de delen over het Nederlands, Fries en Afrikaans, ook door hun onderlinge samenhang, op dit moment al een zeer rijke bron van informatie vormen. Het belangrijkste vergelijkingsmateriaal is de reeks The Phonology of the World's Languages, die bij Oxford University Press verschijnt. Het deel The Phonology of Dutch van Geert Booij (1995) is in bewerkte vorm intensief gebruikt bij de samenstelling van het Nederlandse deel van het fonologische Taalportaal (de eerste druk verscheen nog bij Clarendon Press, een tweede druk verscheen in 1999 bij Oxford University Press). Hoewel ook dit weer lastig te kwantificeren is, lijkt het daarom redelijk om aan te nemen dat het Taalportaal momenteel uitgebreidere informatie bevat dan Booijs boek, onder andere doordat we over meer ruimte beschikten en doordat de fonologie sinds het verschijnen van Booijs boek natuurlijk niet heeft stil gestaan.

Het Nederlandse en het Friese deel staan formeel open voor wijzigingen, maar doordat er geen uitgebreide financiering is voor veel meer dan klein onderhoud, lijkt het irreëel om te verwachten dat er in de nabije toekomst grote nieuwe updates komen (afgezien van een deel over de intonatie van het Nederlands, waaraan nog gewerkt wordt door Carlos Gussenhoven). Aan het Afrikaanse deel wordt momenteel nog actief gewerkt. Ook hiervoor zijn de middelen echter beperkt.

Het commentaar van Ellen Simon \& Anne-Sophie Ghyselen, van Dick Smakman en van Janet Grijzenhout is heel vriendelijk en constructief, en bestaat overwegend uit aanbevelingen om meer informatie toe te voegen. Die aanbevelingen leggen, zoals we hieronder uiteenzetten, allemaal een vinger op een wonde: ze laten manco's zien in het huidige Taalportaal. Dat maakt de constatering dat er aan grote onderdelen van het Taalportaal niet meer systematisch gewerkt wordt, enigszins schrijnend. In deze reactiebijdrage gaan we in op enkele problemen die in de commentaren naar voren worden gebracht, om te besluiten met een suggestie hoe we als fonologische gemeenschap voort kunnen bouwen op het fundament dat in de eerste fase van het Taalportaal gelegd is. We gaan hier overigens voorbij aan de kritiek op redactie en vormgeving van het Taalportaal, omdat deze naar ons oordeel minder interessante stof bieden voor discussie. We zullen er wel naar streven om er in komende updates dankbaar gebruik van te maken. 


\section{$2 \quad$ Variatie in de standaardtaal}

Het commentaar van Simon en Ghyselen en Smakman overlapt, mogelijk doordat beide komen vanuit een variatielinguïstische invalshoek. De convergentie van het commentaar tot zelfs in sommige details (zoals de gevraagde fang voor diftongering) is voor ons overigens een indicatie dat de kritiek serieus dient te worden genomen.

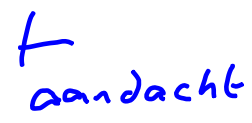

Bij het samenstellen van het Taalportaal is ervoor gekozen uit te gaan van standaardtalen. Zoals Simon \& Ghyselen én Smakman terecht opmerken, heeft dit met name voor het Nederlands tot een aantal belangrijke gaten geleid, die in dit geval ook nog werden verergerd doordat er vrijwel geen systematische aandacht bestaat voor de standaardtaal in Vlaanderen (of, zouden wij willen toevoegen, Suriname). Inderdaad is het Nederlands duidelijk een pluricentrische taal, die bestaat uit drie zeer nauw verwante, maar toch ook, zeker op fonologisch en fonetisch gebied, van elkaar te onderscheiden varianten. Het Taalportaal heeft slechts sporadisch aandacht voor het Belgisch-Nederlands, en vrijwel geen aandacht voor het Surinaams-Nederlands. (Het Caribisch-Nederlands dat Smakman noemt, is dan weer een ander verhaal, omdat het niet duidelijk is in hoeverre dat als gestandaardiseerd kan worden beschouwd.)

Die keuze wordt op de Taalportaalsite ook wel enigszins verdedigd, onder verwijzing naar financiële beperkingen. Oorspronkelijk was de hoop dat er ook een Vlaamse financier gevonden zou kunnen worden, maar die hoop bleek ijdel, zodat het niet mogelijk was om ook in Vlaanderen onderzoekers aan het werk te zetten. De Nederlandse financier NWO heeft vervolgens ook slechts een deel van het aangevraagde geld gehonoreerd, zodat om praktische redenen besloten is het Belgisch-Nederlandse deel uit te stellen tot er wel geld te vinden zou zijn. Helaas is die wens tot op dit moment niet vervuld; we hopen natuurlijk nog steeds dat dit wel gaat gebeuren. Zoals we ook hopen dat er nog mogelijkheden zijn om subsidies te vinden om het deel over de - sowieso nauwelijks beschreven - SurinaamsNederlandse fonologie toe te voegen. Het zou mogelijk moeten zijn om dit te doen. We zijn het met Simon \& Ghyselen eens dat het Taalportaal niet compleet is zonder de beschrijving van op zijn minst die andere standaardtalen, of vormen van de standaardtaal. De financiële overwegingen die tot het neerlandocentristische van het Nederlandse deel hebben geleid, zijn hopelijk wel begrijpelijk, maar leiden inderdaad op dit moment tot een schrijnend gat. (Overigens kun je opmerken dat het Fries buiten Nederland en het Afrikaans buiten Zuid-Afrika ook onderbelicht blijven.) 
Alle drie de casestudies van Simon \& Ghyselen, die min of meer worden geëchood door Smakman, onderstrepen dat nogmaals. Op het gebied van de uitspraak van de diftongen, van stemassimilatie en van vocaalreductie verschillen in ieder geval Nederland en België sterk van elkaar, en wel op manieren die juist ook voor onderzoekers van diverse pluimage van belang zijn. Het is van groot belang het aangehaalde onderzoek over het Standaardnederlands in Vlaanderen te integreren in een toekomstige update van het Taalportaal.

Een andere belangrijke opmerking van Simon \& Ghyselen betreft de status van variatie binnen elk van de standaardtalen - Simon \& Ghyselen richten zich op het Nederlandse deel, maar soortgelijke opmerkingen kunnen zonder twijfel ook worden gemaakt over de delen over het Fries en het Afrikaans: zij vragen zich af 'welk taalgebruik precies als Standaardnederlands (“zoals dat in Nederland wordt gesproken") geldt' en wijzen op de inherente variatie binnen de standaardtaal, ook binnen één land, de sociale gelaagdheid van die variatie, en de verandering waaraan ook de norm onderhevig is (de diftongering van middenklinkers is daar een voorbeeld van).

Er is bij de samenstelling van het Taalportaal, zowel binnen het team dat aan de uitwerking werkte als binnen het Meertens Instituut, dat de gastheer was voor het Nederlandse deel van de fonologische beschrijving, uitgebreide discussie geweest over deze vraag. Het Meertens Instituut richt zich van oudsher vooral op de beschrijving van niet-standaardtalige variatie; het instituut heeft zich in de 21e eeuw juist geprofileerd als een instituut voor variatielinguïstiek. In die zin was het Taalportaal een vreemde eend in de bijt; dit verklaart vervolgens wel dat, zoals Simon \& Ghyselen opmerken, er toch betrekkelijk veel aandacht is voor variatie, ook buiten de standaardtaal, ook al is die aandacht 'niet systematisch'.

Ook aan deze gang van zaken ligt een pragmatische reden ten grondslag. Het Taalportaal is door NWO gefinancierd als een project op het gebied van de onderzoeksinfrastructuur. Het was niet de bedoeling dat er diepgaand origineel onderzoek zou worden gedaan: het project is in de eerste plaats bedoeld als een samenvatting van zoveel mogelijk bestaande literatuur. Onze definitie van de standaardtaal komt daar ook uit voort: we rapporteren als standaardtaal wat in de literatuur als zodanig wordt beschouwd. In de praktijk levert dit overigens weinig problemen op, in ieder geval niet in

$F$ die fè zin datje in de literatuur grote conflicten vindt over wat er nu wel of niet tot de standaardtaal zou moeten worden gerekend.

Het gebied waarover de meeste literatuur was, is ook het gebied waar we iets meer aanvullend, empirisch onderzoek hebben moeten doen: intuïties 
over woordklemtoon van ongelede woorden. Hiervoor hebben we onder andere systematisch naar allerlei soorten woorden in CELEX gekeken, alsmede naar de oordelen van enkele duizenden (overwegend Nederlandse) internetgebruikers over het klemtoonpatroon van door ons geconstrueerde onzinwoorden. We durven wel te zeggen dat dit het pièce de resistance is geworden van het Nederlandse fonologische Taalportaal. Tegelijkertijd is dit, min of meer bij toeval, het verschijnsel waarin Nederlandse variëteiten het minst van elkaar verschillen. Een enkel woord kan in de ene variëteit een andere klemtoon hebben dan in de andere, en in het Belgisch Nederlands is er een iets grotere neiging om in 'vreemde' woorden klemtoon op de voorvoorlaatste lettergreep te leggen (Nederlands-Nederlands: salámi, BelgischNederlands: sálami), maar het complexe klemtoonsysteem lijkt in het hele taalgebied hetzelfde; zoals het ook in het Fries en het Afrikaans niet sterk afwijkt, net zoals ook de klemtoon in andere West-Germaanse talen zoals Duits en Engels zeer sterk lijkt op het door ons vastgestelde. (Dit is op zichzelf een puzzel voor de variatielinguïstiek: hoe is het mogelijk dat een dergelijke ingewikkeld systeem met zo weinig functionele belasting zo weinig variabel is?)

\section{$3 \quad$ De plaats van de fonetiek}

Alle drie de reviewers besteden enige aandacht aan de fonetische informatie die in het Taalportaal gegeven wordt. Deze informatie is inderdaad uiterst summier. De opzet was om informatie samen te vatten over de grammatica van het Nederlands, Fries en Afrikaans, en vandaar lag een beperking tot fonologie, morfologie en syntaxis voor de hand, maar ook de makers van het fonologiedeel hebben het als een beperking ervaren dat er niet meer ruimte was voor fonetische informatie, terwijl er met name voor het Nederlands wel een vrij uitgebreide fonetische literatuur bestaat. De uitzondering zijn de door Koen Sebregts verzorgde beschrijvingen van de individuele fonemen van het Nederlands. In het nog in aantocht zijnde deel over de intonatie van het Nederlands zal naar verwachting ook enige aandacht worden besteed aan de fonetiek van de intonatie.

Dat neemt dus niet weg dat preciezere fonetische details van harte welkom zouden zijn, ook omdat de grenzen tussen fonologie en fonetiek natuurlijk lang niet altijd scherp getrokken kunnen worden (sommige gevallen van reductie bevinden zich natuurlijk duidelijk op de rand), en er ook onderzoekers zijn die het sowieso onwenselijk vinden om deze grens te trekken. Smakman vraagt in dezen bijzondere aandacht voor onderzoekers 
met een sociofonetische belangstelling, die door de op dit moment op het Taalportaal gegeven informatie nog te weinig worden bediend. Ook zulke onderzoekers wil je ter wille zijn.

We zijn het ook met alle recensenten eens dat er in een toekomstige update van het Taalportaal meer gebruik zou kunnen worden gemaakt van geluidsmateriaal; in het recentere Afrikaanse deel is dat ook al veel duidelijker geval dan in de iets oudere Nederlandse en Friese delen. Aan de interface van het syntactische en morfologische deel van het Taalportaal zijn mogelijkheden toegevoegd om bijvoorbeeld bepaalde constructies ook op te zoeken in gestructureerde corpora of zelfs op het internet. De gebruiker kan zo heel veel voorbeelden vinden van de besproken verschijnselen. Voor de fonologie zijn de mogelijkheden veel beperkter, simpelweg omdat er veel minder (of eigenlijk: geen) openbare, eenvoudig doorzoekbare bronnen zijn die op deze manier kunnen worden toegevoegd. Een groot probleem in dezen, dat in het kader van het Taalportaal echter niet kon worden opgelost, is dat er geen via het internet toegankelijke versie (of een equivalent hiervan) van het Corpus Gesproken Nederlands is.

Het belang van het hebben van dergelijke middelen is tegelijkertijd evident: het zou het Taalportaal in één klap een stuk bruikbaarder maken voor studenten Nederlands (of Fries of Afrikaans) in den vreemde, maar ook voor onderzoekers. Wat je eigenlijk ook zou willen, is dat niet alleen de voorbeelden in het fonologische deel, maar ook die in de andere delen door een moedertaalspreker (of zelfs door meerdere, om de variatie aan te tonen) voorgelezen zouden worden. Uiteindelijk is veel morfologische en syntactische literatuur immers in ieder geval nominaal gericht op de gesproken en pas in afgeleide zin op de geschreven taal. Dat men in gedrukte bronnen dan toch alleen geschreven zinnen gebruikt, is een technologische beperking die voor een gedrukte bron eigenlijk niet zou moeten gelden.

We zouden zelfs nog verder willen gaan. De laatste jaren is onderzoek in opkomst dat ook gebruik maakt van audiovisuele middelen, bijvoorbeeld omdat we weten dat bij spraakperceptie ook de vorm van de mond een rol speelt en dat gebaren en gezichtsuitdrukkingen een soortgelijke rol als intonatie kunnen hebben, maar ook doordat we met bijvoorbeeld fMRI en Ultrasound een precies beeld kunnen krijgen van de stand van articulatieorganen, dat ook ons beeld van de klankstructuur uiteindelijk kan bijstellen. In een ideale vorm van het Taalportaal zou ook deze informatie beschikbaar zijn. Smakman wijst er in zijn bespreking terecht op dat het Taalportaal op dit moment geen recht doet aan de variatie in $\sqrt{\text { uitspraak van }}$ de $/ r /$. De enige manier om daar wel recht aan te doen, zou zijn door ook 
zulke middelen in te zetten, en daarnaast, zoals Smakman terecht zegt, een en ander te annoteren voor verschillende vormen van sociale gelaagdheid.

\section{De samenhang tussen de drie talen}

Het commentaar van Grijzenhout lezen we, behalve als een interessante poging om de inhoud van de fonologie als taalwetenschappelijke discipline te structureren, vooral als een kritische beschouwing van de bruikbaarheid van het Taalportaal om de drie behandelde talen op fonologisch niveau met elkaar te vergelijken. We zijn het met haar eens - ze zegt het niet zo expliciet, maar dat beschouwen we vooral als beleefdheid - dat het Taalportaal in dezen op een aantal punten wel te wensen over laat.

Voor een deel is de onvergelijkbaarheid ook bijna niet te voorkomen, zolang er geen algemeen aanvaarde bevindingen zijn over wat de inhoud is van de universele fonologie. De segmentsystemen van de drie talen worden bijvoorbeeld op verschillende manier beschreven. In de studie van ieder van de West-Germaanse talen speelt bij de klinkers en medeklinkers een verschil tussen fortis en lenis een rol, dat echter in ieder van deze talen op een andere manier uitpakt en ook potentieel tot verschillende conclusies leidt over de vraag of dat fortis/lenis-onderscheid nu als lengte of als iets anders moet worden opgevat (en als het iets anders is, wat dan). Daarover zijn m.b.t. de verschillende talen min of meer apart staande discussies gevoerd, en het zou nog een behoorlijk ingewikkeld werk zijn om die op elkaar te betrekken. Het is ook niet helemaal duidelijk of het nodig is om één oplossing te vinden die voor ieder van de talen afzonderlijk werkt. Tegelijkertijd is de kritiek wel terecht dat het goed zou zijn ergens een overkoepelende discussie te hebben die de talen met elkaar contrasteert.

De literatuur over de drie talen staat ook niet helemaal los van elkaar, al is er zoals Grijzenhout terecht opmerkt een asymmetrie die ook in de huidige versie van het Taalportaal weerspiegeld wordt: het Nederlandse deel verwijst nauwelijks naar het Afrikaans en het Fries, terwijl die andere twee wel naar het Nederlands verwijzen (zij het weer niet naar elkaar). Er zijn allerlei sociaal-cultureel-politieke redenen aan te wijzen waarom dit zo is, en sommige zijn zelfs nogal platvloers (met het Afrikaanse project werd begonnen toen het Nederlandse en Friese deel al min of meer voltooid waren), maar die rechtvaardigen deze asymmetrie in het Taalportaal natuurlijk nog niet.

Overigens zou een echt goede overkoepeling van het Taalportaal natuurlijk pas gemaakt kunnen worden als er een nog betere sample van talen 
zou zijn gemaakt. Smakman merkt op dat de keuze voor deze drie talen enigszins willekeurig is en beter verantwoord zou moeten worden. Nu lijkt het ons eigenlijk onmogelijk om op zuiver wetenschappelijke gronden te verantwoorden waarom we Nederlands, Afrikaans en Fries hebben genomen en niet pakweg Italiaans, Veneto en Abruzzese, want natuurlijk zijn alle talen uiteindelijk interessant. Maar het is wel waar dat het Nederlands, Afrikaans en Fries drie West-Germaanse talen zijn en een écht Taalportaal bijvoorbeeld alle West-Germaanse talen, als een interessante sample van talen die niet op micro- of macro-, maar op mesoniveau variëren, zou beschouwen. Er zijn ook wel enige pogingen geweest om ook het Jiddisch en het Duits in het Taalportaal te betrekken (het Engels zou natuurlijk dan ook nog moeten, net zoals minderheidstalen), maar tot op dit moment zijn die niet succesvol. Wel zou een dergelijk portaal van West-Germaanse talen natuurlijk echt unieke kansen bieden voor iedereen die geïnteresseerd is in deze talen, of in grammatica of taalvariatie in het algemeen.

Het is, nogmaals, niet duidelijk of een dergelijk volledig portaal gebaat zou zijn bij al te strakke uniformering van kenmerksystemen, het formaat waarin fonologische regels worden beschreven, enz. Bij taalvergelijking bestaat er altijd een spanning tussen het gebruik van middelen die geschikt zijn voor de individuele taal en middelen die juist de verschillen overstijgen. Wij vermoeden dat het toevoegen van expliciet comparatieve delen, los van de individuele talen, hier de gebruiker beter zou kunnen helpen. Dat neemt niet weg dat we het met Grijzenhout eens zijn dat ook het huidige Taalportaal gebaat zou zijn bij een aantal uniformeringsslagen.

\section{$5 \quad$ Hoe verder?}

De besprekers van het fonologische deel van Taalportaal wijzen op drie belangrijke lacunes in de huidige versie van dit ambitieuze project. We willen een grote website maken waarop iedereen die dat interessant vindt alle bekende informatie kan vinden over de fonologie van het Nederlands, Fries, Afrikaans en als het even kan ool $\sqrt{\text { andere West-Germaanse talen. Alle we- }}$ tenschappelijke literatuur moet worden samengevat en er moeten verwijzingen zijn naar het oorspronkelijk werk - liefst zo, dat je de digitale versies kunt oproepen.

De drie lacunes zijn dat er meer aandacht kan zijn voor variatie, meer voor fonetiek en meer voor een systematische vergelijking tussen de in het Taalportaal vertegenwoordigde talen. De drie lacunes zijn verklaarbaar: ze pasten niet in de eerste opzet die we voor het Taalportaal hadden. 
Tegelijkertijd hoort het vullen van die lacunes wel degelijk wel tot onze uiteindelijke ambities.

De vraag is nu wel hoe we deze uiteindelijke ambities kunnen verwezenlijken. We moeten uiteraard proberen om vervolgsubsidies te krijgen om aan een groter, beter, dieper, rijker Taalportaal te kunnen werken. Degenen die aan de eerste versie hebben gewerkt, zijn daar even verantwoordelijk voor als alle onderzoekers die de idealen delen die aan het Taalportaal ten grondslag liggen.

Tegelijkertijd moeten we, al is het alleen maar vanwege de finesses van het huidige subsidieklimaat, ook rekening houden met andere mogelijkheden. Ons lijkt het een goed idee om het huidige Taalportaal zo snel mogelijk open te stellen voor alle onderzoekers, zodat zij online mee kunnen editen. Het model zou dat van Wikipedia kunnen zijn, zij het dat het verstandig is om deze Wikifonia alleen voor onderzoekers open te stellen. De omweg van het schrijven van besprekingen voor Nederlandse Taalkunde is dan misschien niet meer nodig.

Het Nederlands behoort tot de best beschreven talen ter wereld. Ook het Fries en het Afrikaans zijn, gezien hun sociaal-politieke status en hun absolute aantallen sprekers, uitzonderlijk goed beschreven. Informatie over onze talen is waardevol en in de loop van decennia door heel veel onderzoekers verzameld. Zonder een zo goed mogelijke (digitale) infrastructuur kan deze informatie welpens verloren gaan.

\section{Over de auteurs}

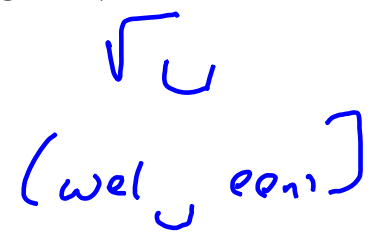

Marc van Oostendorp, Meertens Instituut \& Radboud Universiteit

E-mail:marc@vanoostendorp.nl

Willem Visser, Fryske Akademy \& Rÿhsunive site:t fronijer
E-mail: wvisser@fryske-akademy.nl

Daan Wissing, Centre for Text Technology, North-West University

E-mail: daan.wissing@nwu.ac.za 
